\title{
VARIA
}

\section{FRANCISCO DE GOYA EN SAN NICOLÁS DE LOS LORENESES DE ROMA 1770 '}

La aparición del Cuaderno Italiano de Goya y su posterior estudio por parte de Jesús Urrea $^{2}$, Manuela Mena ${ }^{3}$, Juliet Wilson ${ }^{4}$, Paolo Mangiante ${ }^{5}$, Rogelio Buendía ${ }^{6}$ y Arturo Ansón ${ }^{7}$ ha venido a desvelar un periodo fascinante en la formación del joven Goya, pudiendo rastrear, no solo los elementos que constituyeron sus fuentes en el periodo de aprendizaje, sino los propios orígenes de su arte y sobre todo constituirse en instrumento para fechar y autentificar obras del artista de su época juvenil entre las que destaca el Aníbal vencedor, felizmente hallado por Urrea y con el que Goya concurrió al premio de la Academia de Parma en $1771^{8}$.

Desde la copia del Torso de Belvedere o El Hércules Farnesio a personajes populares romanos que aparecen en dibujos de Hubert Robert o el famoso Scorticato de Houdon, el Cuaderno Italiano constituye un inapreciable testimonio de la curiosidad y devoción creativa del joven Goya entre 1768 y 1770 como ha dejado bien sentado Paolo Mangiante.

En una reciente visita a la ciudad eterna, recalé en la iglesia de San Nicolás de los Loreneses. Al situarme bajo la cúpula y alzar los ojos hacia las pechinas, de repente recordé alguno de los dibujos del Cuaderno Italiano del aragonés. Efectivamente dos de las pechinas representando a La Fortaleza (fig. 2) y La Prudencia (fig. 4) y pintadas por Corrado Giaquinto entre 1731 y $1733{ }^{9}$ fueron copiadas por Goya en las primeras páginas de su Cuaderno Italiano entre 1768 y 1770.

Precisamente Paolo E. Mangiante en su estado de la cuestión del Cuaderno Italiano, se refería a estos dibujos de la siguiente forma:

«Abrir el cuaderno es como abrir de par en par una ventana sobre la Roma tardosetecentista: ojeando sus páginas se puede recorrer buena parte de aquel itinerario

\footnotetext{
I Agradezco a don Emilio Marcos Vallaure las facilidades para la elaboración de este artículo en la Biblioteca del Museo de Bellas Artes de Asturias, a mi amigo Salvador Salort el proporcionarme las ilustraciones de Giaquinto para el presente artículo y a Jesús Urrea la lectura del mismo.

${ }^{2}$ Urrea, J.: «Goya en Italia. A propósito del Aníbal» en Boletín del Museo del Prado, 32, 1993, pp. 59-66

3 Mena Marqués, M.: «Cinco son las magas» en El Cuaderno Italiano 1770-1786. Los orígenes del arte de Goya, Museo del Prado, Madrid, 1994, pp. 15-39

4 Wilson-Bareau, J. y Mena Marqués, M.: Goya. El capricho y la invención, cat. exp., Museo del Prado, Madrid, 1993, pp. $92-98$

5 Mangiante, P.E.: «El Goya italiano: Un estado de la cuestión» en Goya, 244, 1995, pp. 212-226

6 Buendía, R.: «Puntualizaciones en torno al viaje italiano» en Goya, 252, 1996, pp. 353-359

7 Ansón, A.: Goya y Aragón: familia, amistades y encargos artísticos, Zaragoza, 1995

${ }^{8}$ Urrea, J.: Art cit., 1993. Sobre la fuente del Aníbal véase nuestro artículo «El Aníbal de Goya y el modelo de José Arias», en Archivo Español de Arte, 265, 1994, pp. 86-90

9 AA.VV.: Les Eglises Françaises à Rome, Elio de Rosa editore, Roma, 1995, p. 71
} 

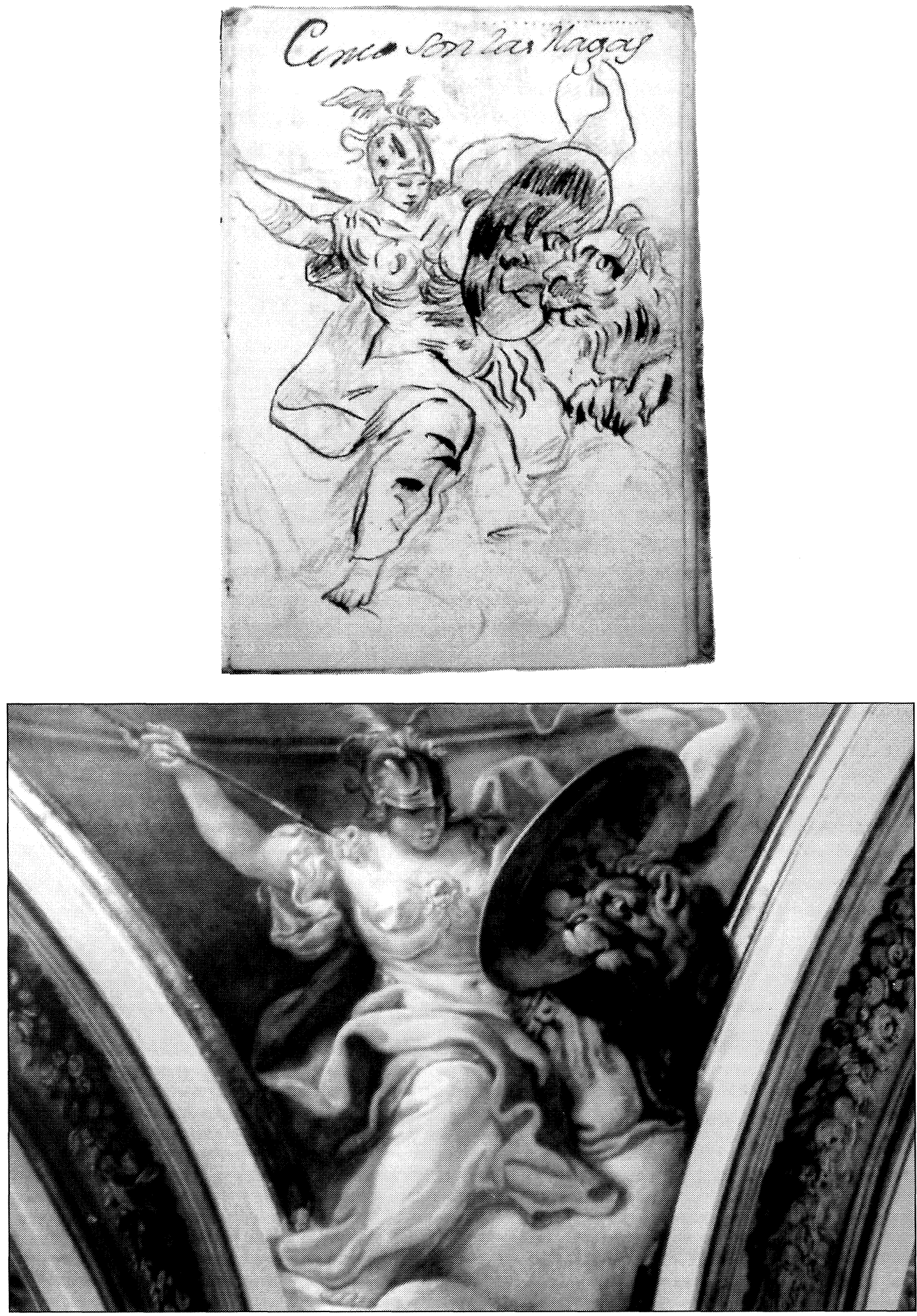

Fig. 1. Francisco de Goya, Alegoría de la Fortaleza, dibujo perteneciente al Cuaderno Italiano, Museo del Prado. Fig. 2. Corrado Giaquinto, La Fortaleza, pechina de San Nicolás de los Loreneses, de Roma.

AEA, LXXV, 2002, 299, pp. 293 a 334 

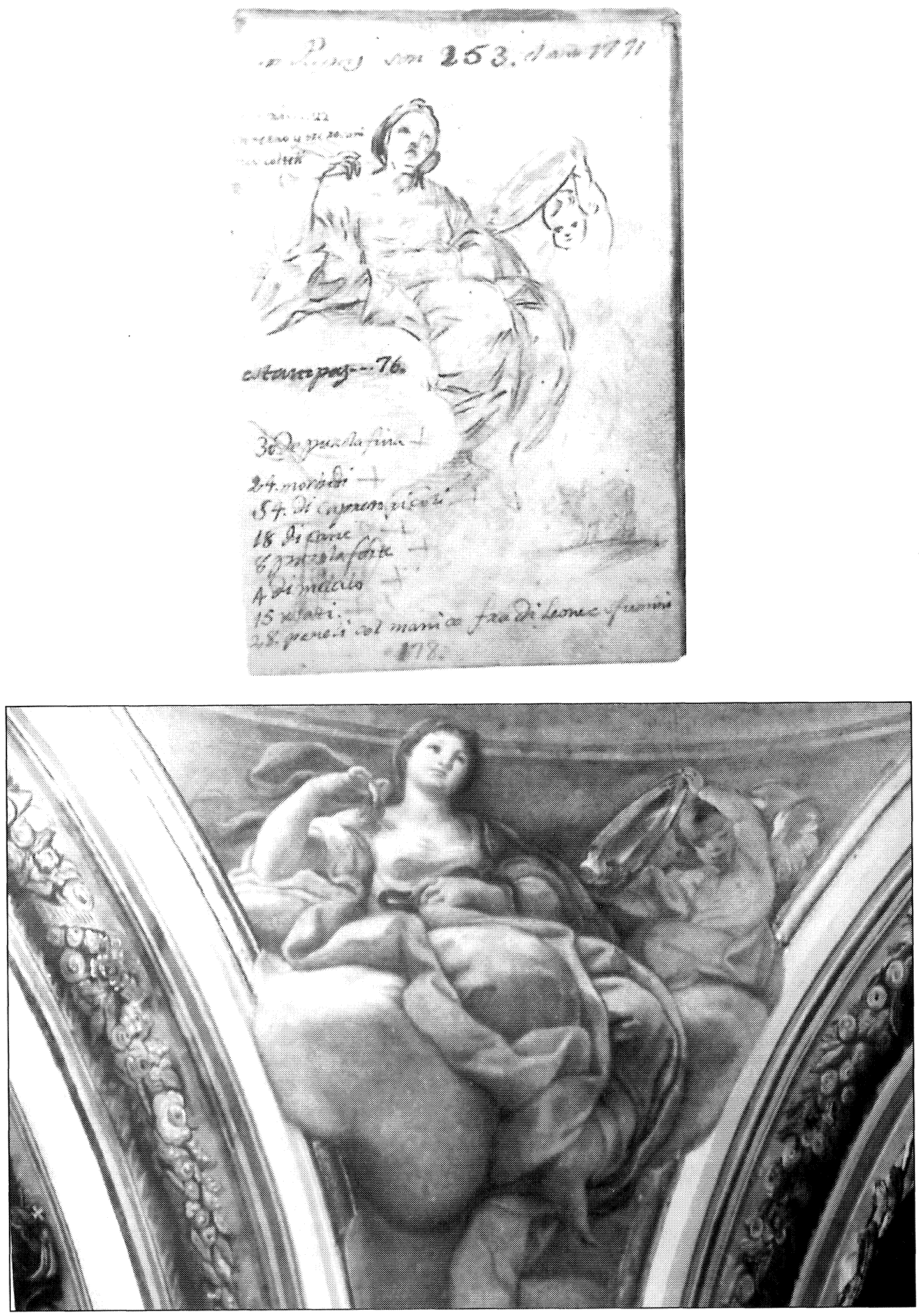

Fig. 3. Francisco de Goya, Alegoría de la Prudencia, dibujo perteneciente al Cuaderno Italiano, Museo del Prado. Fig. 4. Corrado Giaquinto, La Prudencia, pechina de San Nicolás de los Loreneses de Roma.

AEA, LXXV, 2002, 299, pp. 293 a 334 
pictórico romano...El aire romano se respira desde los primeros folios. Enseguida nos enfrentamos a dos alegorías femeninas de claro antecedente giaquintesco» ${ }^{10}$.

Tanto la alegoría de La Fortaleza (fig. 1) que presenta inscripción diciendo «Cinco son las Llagas»" como la de La Prudencia (fig. 3) testimonian, una vez más, el seguimiento de los modelos de Giaquinto, algo fundamental en el Goya joven, como ya señaló Rogelio Buendía ${ }^{12}$. Esta pequeña contribución pretende localizar un lugar indudable en el periplo romano de Goya y completar el estudio del cuaderno, identificando una nueva fuente.

Pero la pregunta que debemos hacernos, a la luz de la estancia incuestionable de Goya en esta iglesia romana es la razón de su visita. San Nicolás de los Loreneses es iglesia de fundación francesa que fue reconstruida en 1635 y sufrió una renovación en 1730. Entre 1731 y $1733{ }^{13}$ Corrado Giaquinto realiza una serie de frescos entre los que se encuentran San Nicolás haciendo brotar el agua de una roca en la bóveda principal de la iglesia, Las cuatro virtudes cardinales en las pechinas de la cúpula del crucero, Las tres virtudes teologales en la cúpula del presbiterio, La Trinidad y San Nicolás en la cúpula del crucero, El Angel liberando un prisionero sobre el muro de entrada de la iglesia. Con ocasión del jubileo de 1750 Corrado Giaquinto volvió a decorar la iglesia con diez cuadros con escenas de la vida de San Nicolás. Por lo tanto, es iglesia en la que se conservan bastantes obras de este artista, razón por la cual la visita era obligada.

Benito Navarrete Prieto Universidad de Valladolid

\section{VELÁZQUEZ COMO PADRINO DE NIÑOS DE LA FURRIERA}

En este pequeño artículo deseamos dar a conocer varios documentos referidos a Velázquez como padrino de bautizos de hijos de empleados de la furriera, que han sido encontrados en los libros de bautizos de la antigua parroquia de San Juan en Madrid, y que se no se recogen dentro de la exhaustiva recopilación de textos que sobre el autor se editó el pasado año 2000 bajo el título Corpvs Velazqveño.

Los diferentes cargos dentro de Palacio vinieron impuestos por Carlos V, quien introdujo la etiqueta borgoñona en España, llevada a efecto con su hijo Felipe II, con el que se van a

\footnotetext{
${ }^{10}$ Mangiante cita la alegoría de la Prudencia como la Verdad? diciendo ser copia de las figuras alegóricas ejecutadas por Giaquinto para la Casita del Príncipe en El Escorial y la alegoría de la Fortaleza como copia de la pintada por Giaquinto para el Palacio Real de Caserta. Cfr. Mangiante, Art cit., 1995, pp. 213-214. Para Giaquinto y Goya véase también del mismo autor Goya e l'Italia, Palombi editori, Roma, 1992. También Arturo Ansón ha mencionado las «referencias giaquintescas» en estas alegorías. Cfr. «La formación artística de Goya y la etapa Zaragozana, 1759-1774» en Goya 250 Aniversario, cat. exp., Museo del Prado, Madrid, 1996, p. 61.

${ }^{11}$ En la edición facsímil del Cuaderno Italiano hay una lectura incorrecta de la presente inscripción. No es Nagas ni Magas sino Llagas, haciendo clara referencia a las cinco llagas de Cristo que fueron objeto de culto en algunos lugares de Italia y España.

12 Buendía, R.: «La influencia de Corrado Giaquinto en Goya y su entorno» en Actas del II Congreso de Historia del Arte, Valladolid, 1978, pp. 30-37. Véase también del mismo autor; «El aprendizaje Italiano» en Jornadas en torno al estado de la cuestión de los estudios sobre Goya, Madrid, 1992, pp. 15-23.

13 Véase Violette, P.: «La décoration de l'eglise de Saint-Nicolas-des-Lorrains (1623-1870)» en Les Fondations nationales dans la Rome Pontificale, Roma, 1981, p. 494 y del mismo autor «Les travaux de Corrado Giaquinto dans l'eglise de Saint Nicolas des Lorrains à Rome» en Corrado Giaquinto (1703-1766). Atti del II Convegno Internazionale di Studi, Molfetta, 1985, pp. 113 y ss.
}

AEA, LXXV, 2002, 299, pp. 293 a 334 